\title{
Production of Ethanol from Cassava Peelings Using a Developed Percolation Reactor
}

\author{
Titiladunayo Isaac Femi1 ${ }^{*}$, Ibitowa Olayinka Ahmed1, Ogunsuyi Olayinka Helen², \\ Jagannadh Satyavolu ${ }^{3}$
}

\author{
${ }^{1}$ Department of Mechanical Engineering, School of Engineering and Engineering Technology, The Federal University of \\ Technology, Akure, Nigeria \\ ${ }^{2}$ Department of Chemistry, School of Sciences, The Federal University of Technology, Akure, Nigeria \\ ${ }^{3}$ Conn Center for Renewable Energy Research, University of Louisville, Louisville, USA \\ Email: ^ftitiladunayo@yahoo.com
}

How to cite this paper: Femi, T.I., Ahmed, I.O., Helen, O.O. and Satyavolu, J. (2018) Production of Ethanol from Cassava Peelings Using a Developed Percolation Reactor. Journal of Sustainable Bioenergy Systems, 8, 107-115.

https://doi.org/10.4236/jsbs.2018.84008

Received: September 24, 2018

Accepted: November 18, 2018

Published: November 21, 2018

Copyright $\odot 2018$ by authors and Scientific Research Publishing Inc. This work is licensed under the Creative Commons Attribution International License (CC BY 4.0).

http://creativecommons.org/licenses/by/4.0/

\begin{abstract}
Bioethanol is an important product in the fuel market obtainable from biomass through fermentation process but direct conversion of cassava peelings to bioethanol as energy by-product is difficult because of its lignocellulosic content. This paper therefore, considers the intermediate route of converting lignocellulosic biomass to fermentable sugar through acid hydrolysis and consequent ethanol production, in a developed percolation reactor. Cassava tuber consists of the starchy flesh and peelings that can be converted into bioethanol but the main agro-waste from cassava crop, aside from the leaves and stem is the peelings. The level of cultivating of the crop in Nigeria is exceptionally high as practised in other developing nations, yet there is no significant use for its peelings which is generated in thousands of metric tonnes annually. Therefore, apercolation reactor is designed for the thermochemical pre-treatment of the lignocellulosic biomass through hydrolysis process with a view to recovering the reducing sugars for fermentation. The reactor is designed to hold $2 \mathrm{~kg}$ of pulverised cassava peelings of $0.5 \leq$ and $\geq 0.3 \mathrm{~mm}$ particle size and circulate $3 \mathrm{~L}$ of acid liquor for each hydrolysis run. The reactor comprised of a $0.0261 \mathrm{~m}^{3}$ perforated basket, $1.83 \mathrm{~W}$ capacity circulation pump in power rating, and a heating chamber containing $3 \mathrm{~kW}$ heater. The reactor is designed to operate within the temperature range of $20^{\circ} \mathrm{C}-180^{\circ} \mathrm{C}$, pressure $\leq 45 \mathrm{Nm}^{-2}$, and liquor flow rate of $4.33 \times 10^{-4} \mathrm{~m}^{3} \cdot \mathrm{S}^{-1}$. The reactor was used to convert $500 \mathrm{~g}$ of pulverised cassava peelings to sugar laden hydrolysate that subsequently yielded $118 \mathrm{~mL}$ of bioethanol through fermentation process in three replicated experiments. The designed percolation reactor could therefore serve as a veritable tool in converting biomass of lignocellulosic origin to chemical and energy products, reduce wastes and promote cleaner environment.
\end{abstract}




\section{Keywords}

Cassava Peeling, Percolationreactor, Hydrolysis, Bioethanol

\section{Introduction}

Lignocellulose wastes are accumulated every year in large quantities, causing environmental problems. However, due to their chemical composition which consist of complex sugars and other compounds of interest, they could be utilized for the production of a number of value added products, such as ethanol, food additives, organic acids, enzymes, and others [1]. Therefore, besides the environmental problems caused by their accumulation in the nature, the non-use of these materials constitutes a loss of potentially valuable sources. Lignocellulosic materials predominantly contain a mixture of carbohydrate polymers (cellulose and hemicellulose), lignin, extractives, and ashes [2]. These constituents are bonded together by chains and these chains are packed by hydrogen bond in so called "elementary fibrils" originally considered to be 3 to $4 \mathrm{~nm}$ wide and contain about 36 chains, although larger crystalline fibrils up to $16 \mathrm{~nm}$ were also discovered [3]. The constituents are closely associated with each other constituting the cellular complex of the vegetal biomass.

Cassava (Manihotesculenta Crantz) has been an important crop used for food and industrial purposes in most Africa countries. Cassava is the chief source of dietary food energy for the majority of the people living in the lowland tropics, and much of the sub-humid tropics of West and Central Africa [4]. Its production is vital to the economy of Nigeria at the country is the world's largest producer of the farm produce. Cassava is composed of large amounts of starch $(20 \%$ - 35\% fresh and $80.6 \%$ dry weight) [5] [6] and total dry matter (38.6\%) [7], and has been reported to have the smallest water-footprint $\left(21 \mathrm{~m}^{3} / \mathrm{GJ}\right)$ compared to all other crops [8]. Based on the above reasons, cassava has recently gained considerable attention as in important lignocellulosic biomass for the production of bioenergy [6]. The most important characteristics of cassava is that it contains $\mathrm{C}_{3}$ and $\mathrm{C}_{4}$ photosynthetic root and these promotes carbohydrates production to some extent that the plant is suitable for industrial utilization.

In processing cassava tuber, the biomass left behind include peelings, leaves and roots, and in most cases, the biomass waste is not used for any economical purposes. Apart from the stem that may be used for re-planting, the peelings are usually disposed of indiscriminately, thus leading to environmental pollution. In the best cases, the current utilisation of cassava peelings includes its potential re-placement for maize in animal feed, especially for ruminant animals. However, the drawback in this include; its low protein content $(<6 \%)$ [9], and the presence of anti-nutrients such as hydrocyanic acid, tannic acid, oxalic acid which could produce hazardous effects on ruminant animals [10]. Consumption of cassava wastes is therefore greatly reduced, leaving the residue as non-valuable 
wastes in the environment compartment. However, the wastes could be of tremendous value if utilized for energy generation.

In Nigeria, the quantity of cassava peelings generated is quite huge in places where gari (dried cassava flour), fufu (wet cassava flour) and Starch are produced and converting such wastes to energy resources would consume the wastes, sanitize the environment and benefit the nation economically. One of the ways to unlock this great potential of the waste is by getting valuable products out of it, hence, a reactor was being designed to hydrolyse the waste. In this research work, a percolation reactor was designed as described by [11] to check its efficiency for the hydrolysis of agricultural waste such as cassava peelings.

Many researchers have reported on the use of different reactors such as Stir-tank, Plug flow, Batch reactors etc. for the hydrolysis of biomass. Batch reactor has been the most widely us for kinetic study of hydrolysis and laboratory study of bioethanol derived there from [12] and [13]. However, [11] reported the use of percolation reactor towards an integrated biorefinery using a dried distillers' grains and achieved a high pentose yield using a percolation reactor with liquid re-circulation. Hitherto, information about the use of percolation reactor for the hydrolysis of cassava waste is scanty and has not been found reported in literature. Therefore, this research work preferentially considered percolation reactor over others due to its advantages at reducing acid consumption, higher yield of hemicellulose sugars and lower yield of sugar degradation products [14] and [15]. Furthermore, unlike the batch and plug flow reactors, this percolation reactor does not need a solid or liquid separation as the solid are placed in the percolation baskets and do not flow with the liquid. Therefore, damages due to particle attrition are minimal in this reactor when compared to other types of reactor.

\section{Material and Methods}

\subsection{Materials}

The Percolation reactor is made of two concentric cylinders. The inner cylinder is of $270 \mathrm{~mm}$ diameter, $456 \mathrm{~mm}$ height, $3 \mathrm{~mm}$ thickness and made of galvanised plate while the outer cylinder is of $370 \mathrm{~mm}$ diameter, $456 \mathrm{~mm}$ height, $3 \mathrm{~mm}$ thickness and made of mild steel. Mild steel was used because it is available, cheap and has the ability to withstand high temperature. The galvanised plate was used for the inner cylinder because of its relatively lower cost and corrosion resistant properties. A lagging material (fibreglass) which is $50 \mathrm{~mm}$ in thickness was sandwiched between the inner and outer cylinders to prevent heat lost or gain in the reactor chamber. A discharge outlet was incorporated into the reactor for the collection of the hydrolysed samples at various predetermined time intervals. The base of the reactor chamber was made conical in shape, for an easy discharge of the hydrolysate, at the end of each hydrolysis process and to facilitate cleaning after use. A perforated material holding basket of 297 microns mesh size, is placed inside the inner cylinder and could be removed or replaced 
with the aid of an attached handle. A heating compartment through which the hydrolyzate circulates was attached to the reactor and powered by a $3000 \mathrm{~W}$ heating element. The temperature of the component was controlled and regulated by a Type- $\mathrm{K}$ thermocouple and a temperature controller at desired set points. The rate of hydrolyzate circulation and pressure was controlled by a variable speed pump of 0.5 hpcapacity. A control box that superintends and monitors the entire operation of the percolation reactor was designed and incorporated into the reactor. The reactor was designed based on the following considerations: rapid pumping of hydrolyzate, reliable heat supply for heating the system, rapid heat transfers into the reactor, avoiding heat loss and maintaining a set temperature during operation. The schematic diagram of the Percolation reactor is shown in Figure 1.

\section{Sample Collection and Pretreatment}

The cassava peelings used for this research work was obtained at various Gari processing sites at Ilara-Mokin, Ondo State of Nigeria. $20 \mathrm{~kg}$ of the fresh cassava peelings was obtained from various processing sites at Ilara-Mokin, cleaned to remove adhering sand grains, dirt, dust and of other impurities. The cleaned peels were sundried for 3 days to reduce the moisture content to about 6 - 8 wt\%; and then ball milled to obtain $0.5 \leq$ and $\geq 0.3 \mathrm{~mm}$ particle size (Figure 2) using Denver ball mill Model 230994. This particle dimension provided a high surface area per unit volume of the feedstock and prevented particle clogging on the material holding basket. The particles attain the desired hydrolysis temperature, within a very short residence time because of their small linear dimensions and permit easy acid penetration through their pores. The complex organic structural bond is broken through this process and complex sugars are reduced to simple sugars, in a process termed hydrolysis.

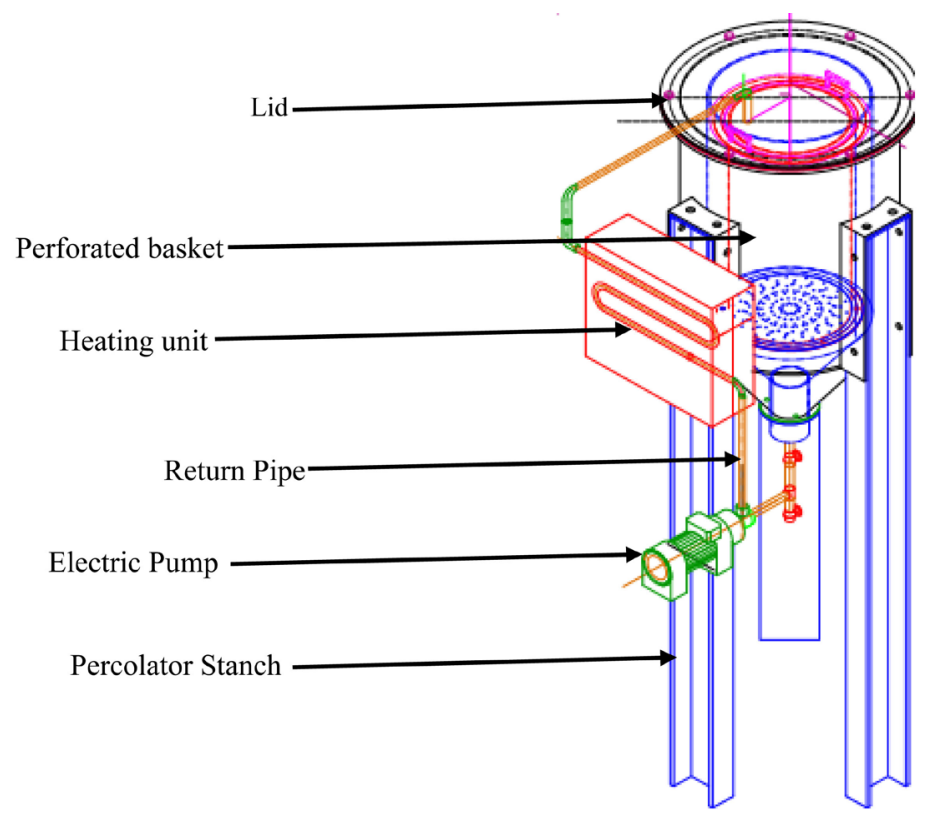

Figure 1. A percolation reactor for the hydrolysis of agricultural biomass waste. 


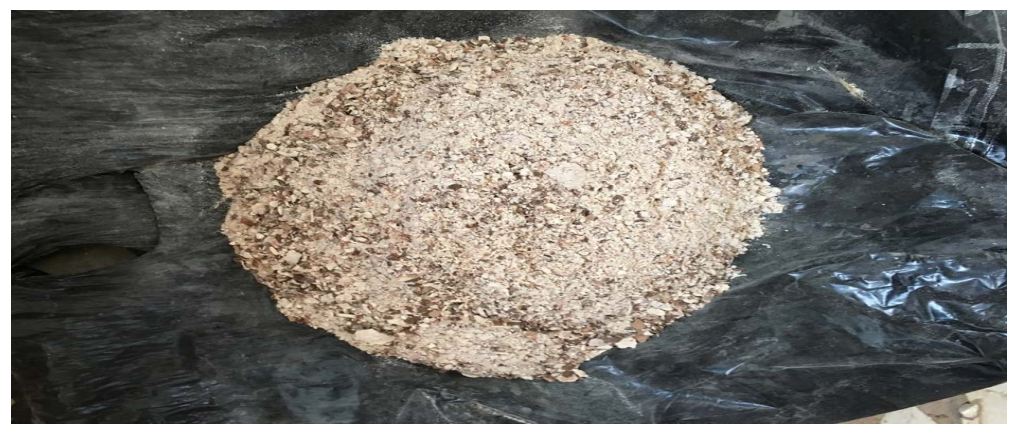

Figure 2. Milled cassava peelings.

\subsection{Methods}

The conversion of agricultural biomass wastes such as cassava peelings to ethanol is not obtained through a direct route, hence the developed percolation reactor (Figure 1) will be used in breaking its structural bonds and thus releasing the fermentable sugar before been fermented. Figure 3 outlined the conversion stages of the biomass from pre-treatment process to bioethanol production stage.

\subsubsection{Hydrolysis}

$500 \mathrm{~g}$ of milled cassava peelings was collected and hydrolysed using $250 \mathrm{~mL}$ of $0.5 \mathrm{M}$ dilute sulphuric acid $\left(\mathrm{H}_{2} \mathrm{SO}_{4}\right)$ in 2 litres of distilled water at a temperature of $100^{\circ} \mathrm{C}$ for a duration of 2 hours. The hydrolysis of the feedstock samples was done in three replicate experiments. The hydrolyzate (Figure 4) obtained from the reaction showed an acidic property and thereafter subjected to neutralization process.

\subsubsection{Neutralization of the Cassava Hydrolyzate}

$10 \mathrm{~g}$ of $\mathrm{NaOH}$ was dissolved in $500 \mathrm{~mL}$ of distilled water to obtain a solution of $0.5 \mathrm{M}$ sodium-hydroxide. The solution of $\mathrm{NaOH}(0.01 \mathrm{M})$ was added in drops to the hydrolysate and the neutralization level was measured to be 7.2 with a $\mathrm{pH}$ meter.

\subsubsection{Fermentation of the Cassava Peelings Hydrolyzate}

The cassava hydrolyzate was fermented at room temperature (Figure 5). $20 \mathrm{~g}$ of yeast (Saccharomyces cerevisiae) was added to the hydrolyzate to aid fermentation and the fermentation lasted for 7 days. As fermentation days reached the last day, $\mathrm{CO}_{2}$ is shown to have evolved at the surface of the fermented liquor (Figure 5).

\subsubsection{Distillation of the Fermented Product}

The fermented liquor was distilled using Liebig condenser apparatus. The fermented liquor was distilled at a temperature ranging from $77^{\circ} \mathrm{C}-80^{\circ} \mathrm{C}$. The distillate collected at that temperature was re-distilled and the distillate was collected at a temperature of $78^{\circ} \mathrm{C}-78.4^{\circ} \mathrm{C}$ where the standard boiling temperature for ethanol production is $78.3^{\circ} \mathrm{C}$ 


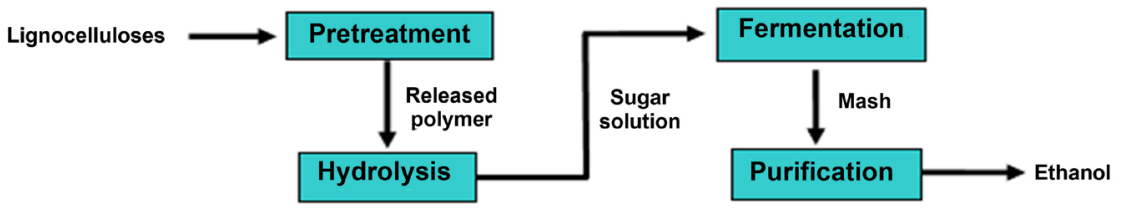

Figure 3. Conversion stages of cassava peels biomass to Ethanol.

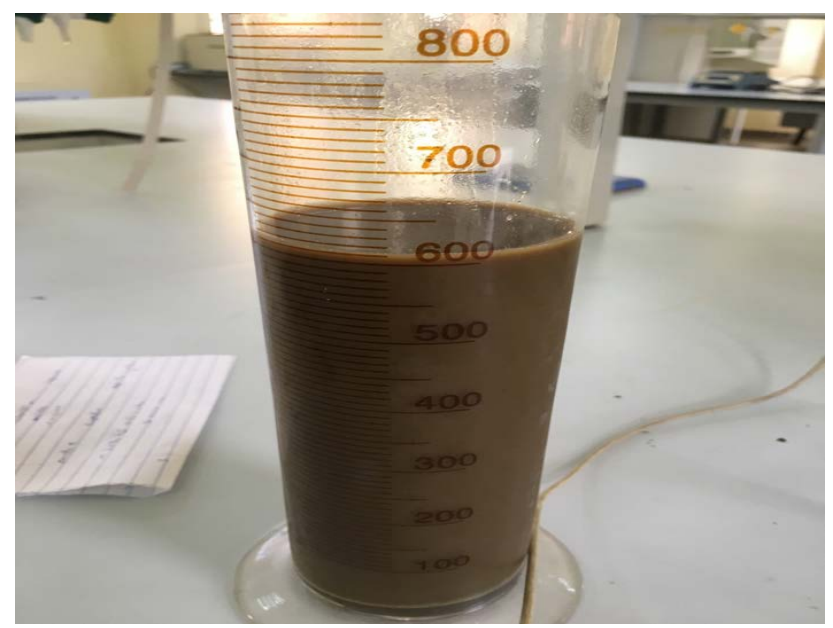

Figure 4. Hydrolyzate from cassava peelings.

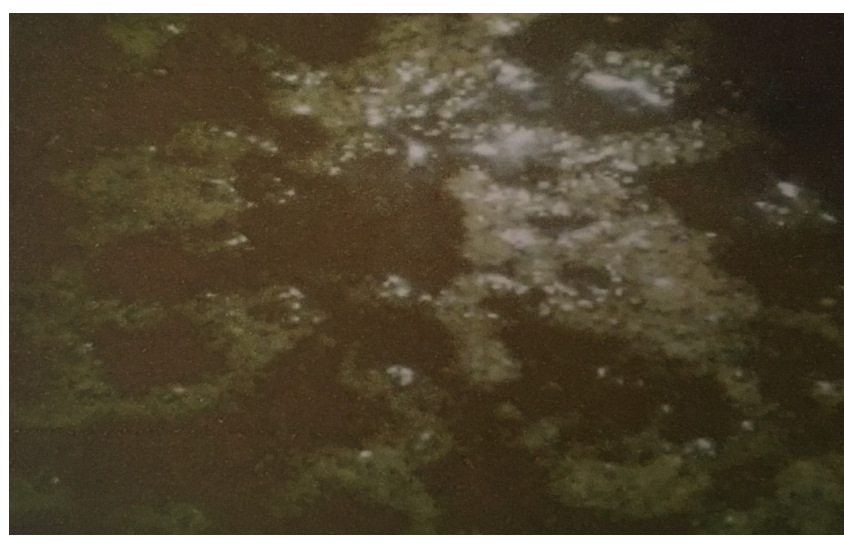

Figure 5. Fermentation of the cassava peels hydrolyzate.

\section{Results}

\subsection{Fourier Transform Infrared (FT-IR) Test of the Ethanol Produced}

A functional group identification test was carried on the ethanol using a Fourier Transform Infrared (FT-IR) spectrophotometer at the Department of Chemistry, University of Ibadan, Ibadan, Oyo State Nigeria. The result is presented in Figure 6 and Table 1.

\subsection{Fuel Properties of Ethanol Produced}

Table 2 shows the fuel properties of the ethanol produced compared to the standard properties of ethanol reported by [16]. 
Table 1. FT-IR structural information of the cassava peel bioethanol.

\begin{tabular}{cccc}
\hline S/N & Functional Group & Absorption location $\left(\mathrm{cm}^{-1}\right)$ & Absorption Intensity \\
\hline 1 & Alcohol & 3282.00 & Strong \\
2 & Alkane & $2897.60-2976.20$ & Strong \\
3 & Nitrile & 2249.8 & Medium \\
4 & Alkyne & 2133.04 & Medium \\
5 & Aromatics & 1649.41 & Weak \\
\hline
\end{tabular}

Table 2. Fuel properties of ethanol produced compared to the standard properties.

\begin{tabular}{cccc}
\hline S/N & Properties & Ethanol Produced & $\begin{array}{c}\text { Standard Ethanol reported } \\
\text { by [16] }\end{array}$ \\
\hline 1 & Boiling point, ${ }^{\circ} \mathrm{C}$ & 78.4 & 78 \\
2 & Density at $15^{\circ} \mathrm{C}$ g/mL & 0.785 & 0.789 \\
3 & Specific gravity & 13 & 13 \\
4 & Viscosity at $20^{\circ} \mathrm{C}$ & 0.0013 & 0.0012 \\
5 & pH & 7.2 & - \\
6 & Pour point & -39 & -40 \\
7 & Refractive index, \% & 1.3803 & - \\
\hline
\end{tabular}

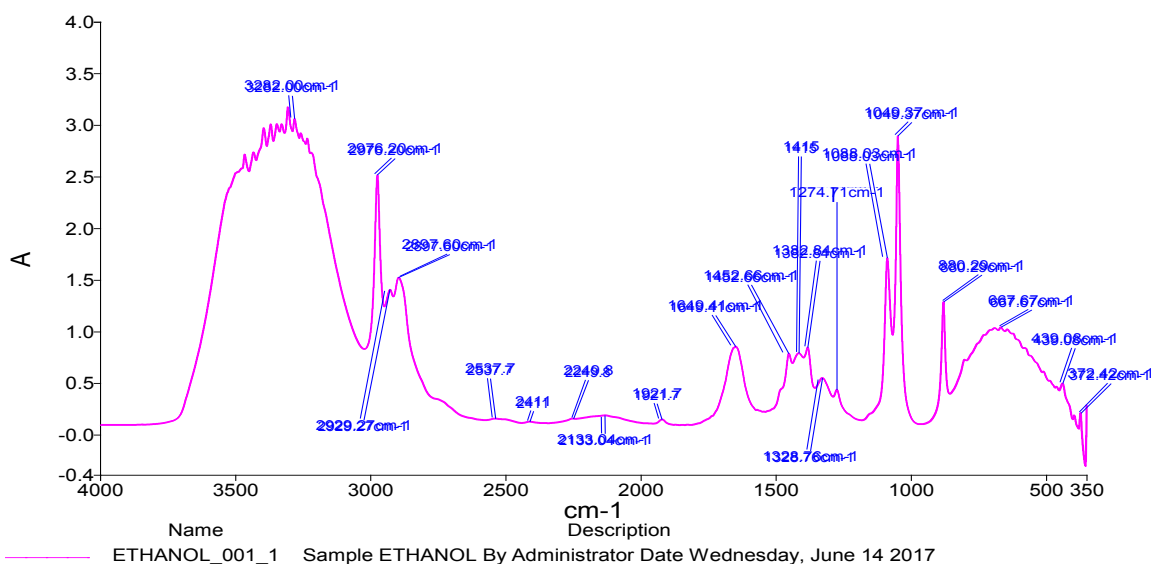

Figure 6. FT-IR spectrum of the ethanol produced.

\section{Discussion}

The FT-IR spectra in Figure 6 range from high energy cosmic rays (high frequency, short wavelength) to very low energy microwaves (low frequency, long wavelength). The spectra of the ethanol were measured as absorbance (Figure 6). The percentage of light that passed through the ethanol sample for every wavelength was shown in Figure 6. The graph of the absorbance (Figure 6) explains that, the highest level of wavelength sample is predominantly characterised by $\mathrm{OH}$ group. Alcohol (OH-group) is said to occur at a wavelength ranging from $3500-3000 \mathrm{~cm}^{-1}$ and the spectra indicate the presence of OH-group at 3280 
$\mathrm{cm}^{-1}$ which is a strong alcohol (Table 1). Other functional groups were also found in the ethanol and they belong to the alkane, nitrile, alkyne and aromatic group (Table 1).

\section{Conclusion}

The percolation reactor was developed and fabricated using locally available materials, while ethanol production was achieved using cassava peelings as feedstock. The reactor is simple to operate, easy to maintain and affordable. The reactor was used to hydrolyse $500 \mathrm{~g}$ of cassava peelings thrice in a replicating experiment that produced a mean value of $118 \mathrm{~mL}$ of ethanol per run. The physicochemical, thermochemical and energy characteristics of ethanol produced was determined (Table 2) and compared with the properties of ethanol reported by [16], while the spectraanalysis (Figure 6 and Table 1) was done using F.T.I.R spectrophotometer. These properties were consistent with standards aside from a minute observed difference of $0.04 \mathrm{~g} / \mathrm{mL}$ in its density, which highly suggests that the product is ethanol. Therefore, the use of the percolation reactor for the hydrolysis of biomass waste prior to the production of ethanol is an effective way of generating fermentable sugar from the biomass wastes. In addition, hydrolysis is a promising route for converting biomass wastes to chemical and energy products, consume accumulation of agricultural wastes in the environment, prevents its biodegradation and promote cleaner environment.

\section{Conflicts of Interest}

The authors declare no conflicts of interest regarding the publication of this paper.

\section{References}

[1] Mussatto, S.I. and Teixeira, J.A. (2010) Lignocellulose as Raw Material in Fermentation Processes. In: Mēndez-Villas, A., Ed., Current Research Technology \& Education Topics in Applied Microbiology \& Microbial Biotechnology, Formatex Research Centre, Bad Ajoc. 2: 897-907.

[2] Taherzadeh, M.J. and Karimi, K. (2007) Acid-Based Hydrolysis Processes for Ethanol from Lignocellulosic Materials: Bioethanol Review. BioResources, 2, 707-738.

[3] Ha, M.A., Apperley, D.C., Evans, B.W., Huxham, M., Jardine, W.G., Vietor, R.J., Reis, D., Vian, B. and Jarvis, M.C. (1998) Fine Structure in Cellulose Microfibrils: NMR Evidence from Onion and Quince. The Plant Journal, 16, 183-190. https://doi.org/10.1046/j.1365-313x.1998.00291.x

[4] Tsegai, D. and Kormawa, P.C. (2002) Determinants of Urban Household Demand for Cassava Products in Kaduna, Northern Nigeria. In: Conference of International Research for Development, Witzenhause, 9-10.

[5] Chang, S., Zhao, L., Timilsina, G.R. and Zhang, X. (2012) Biofuel Development in China: Technology Options and Policies Needed to Meet the 2020 Target. Energy Policy, 51, 64-79. https://doi.org/10.1016/j.enpol.2012.05.084

[6] Truman, P.P., Daphne, S.T., Lateef, S. and Malachy, O.A. (2004) A Cassava Industrial Revolution in Nigeria. The Potential for a New Industrial Crop. International 
Fund for Agricultural Development (IFAD), Food and Agriculture Organization of the United Nations. 1-49.

[7] Kuiper, L., Ekmekci, B., Hamelinck, C., Hettinga, W., Meyer, S. and Koop, K. (2007) Bioethanol from Cassava. Ethanol from Cassava. Ecofys Netherlands BV, Utrecht.

[8] Wang, W. (2002) Cassava Production for Industrial Utilization in China-Present and Future Perspective, Cassava Research and Development in Asia: Exploring New Opportunities for an Ancient Crop. Proceedings of the 7 th Regional Workshop, Bangkok, 33-38. http://books.google.com/

[9] Tewe, O.O. (1992) Detoxification of Cassava Products and Effects of Residual Toxins on Consuming Animals. Food and Agricultural Organisation, Animal Production and Healthpaper, 95, 81-98.

[10] Oluremi, I.A. and Nwosu, A. (2002) The Effect of Soaked Cassava Peels on Weanling Rabbits. Journal of Food Technology in Africa, 7, 12. https://doi.org/10.4314/jfta.v7i1.19311

[11] Dania, A.F., Robert, L., David, T., Mayank, G. and Jagannadh, S. (2014) Towards Integrated Biorefinery from Dried Distillers' Grains: Selected Extraction of Pentoses Using Dilute Acid Hydrolysis. Biomass and Bioenergy, 71, 178-186.

[12] Brandberg, T., Sanandaji, N., Gustafsson, L. and Franzen, C.J. (2005) Continuous Fermentation of Undetoxified Dilute Acid Lignocellulose Hydrolysate by Saccharomyces cerevisiae ATCC 96581 Using Cell Recirculation. Biotechnology Progress, 21, 1093-1101. https://doi.org/10.1021/bp050006y

[13] Carvalheiro, F., Duarte, L.C. and Gírio, F.M. (2008) Hemicellulose Biorefineries: A Review on Biomass Pretreatments. Journal of Scientific \& Industrial Research, 67, 849-864.

[14] Yang, B. and Wyman, C.E. (2004) Effect of Xylan and Lignin Removal by Batch and Flow through Pretreatment on the Enzymatic Digestibility of Corn Stover Cellulose. Biotechnology and Bioengineering, 86, 88-95. https://doi.org/10.1002/bit.20043

[15] Lee, Y.Y., Iyer, P. and Torget, R.W. (1999) Dilute-Acid Hydrolysis of Lignocellulosic Biomass. Advances in Biochemical Engineering/Biotechnology, 65, 93-115. https://doi.org/10.1007/3-540-49194-5_5

[16] Perry, R.H., Green, D.W. and Maaloncy, J.O. (1997) Perry's Chemical Engineer's Handbook. McGraw-Hill Book Company, Inc., New York, Toronto, London. 